\title{
Miscibility of Perylene Derivatives with Fatty Acid in Two-Dimensional Binary Mixture
}

\author{
J. MAKOWIECKI AND T. MARTYNSKI* \\ Faculty of Technical Physics, Poznań University of Technology, 60-965 Poznań, Poland \\ (Received January 29, 2014; in final form March 11, 2014)
}

\begin{abstract}
Two component mixtures of a fluorescent perylene dye (derivative of 3,4,9,10-perylenetetracarboxylic acid) with arachidic acid in the whole range of mole fraction have been investigated in form of molecular monolayers at the air-water interface at different $\mathrm{pH}$ of the water subphase. Miscibility of the components in the Langmuir monolayers have been examined for $\mathrm{pH} 3$ and $\mathrm{pH} 13$ of the subphase. Using the Langmuir-Blodgett technique the monolayers were transferred onto freshly cleaved mica sheets and morphology of the films was analyzed using atomic force microscopy working in tapping mode. Investigation of the components miscibility in monolayers, determined by mean molecular area and surface pressure analysis reveals different behavior of the mixtures depending on $\mathrm{pH}$ of the subphase. Atomic force microscopy morphology images of the Langmuir-Blodgett films strongly support conclusion about the components mixing and coverage of the mica surface. It has been found that onto acidic subphases components are only miscible in vestigial form, whereas on alkaline the miscibility is strongly affected by the dye concentration.
\end{abstract}

DOI: 10.12693 /APhysPolA.126.757

PACS: 68.18.-g, 68.47.Pe, 64.75.Jk, 64.75.St

\section{Introduction}

Miscibility in multicomponent systems is important not only from scientific but also technological point of view because mixtures possess important physico-chemical properties. Miscibility parameters of the components in bulk samples (3D) may not be the same as in molecular layers at the interface (2D). Miscibility or phase separation in monomolecular films are of utmost importance in functionality of native or artificial membranes and sensors. Fabricating layers with thickness corresponding to single molecule dimensions and small number of defects on large areas combined with possibility of producing mono- and multilayer systems gives an opportunity for many applications, e.g. as sensors, active layers in organic light-emitting diodes (OLED), non-linear optics, as an active layer or insulators in molecular electronics. One of the best technologies for creating well organized molecular layers onto the air-liquid and the air-solid interface are Langmuir and Langmuir-Blodgett (LB) techniques. However, these methods for monolayer creation require specific properties of the material used. In the first step the monolayer is compressed at the airwater interface, which needs amphiphilic (surface active) properties of the molecules and transfer onto solid support under particular conditions. Only a part of substances possess such feature. In other cases it is possible to mix interesting compound with monolayer building agents. The problem of mixing of the compounds in two-dimensional (2D) systems has to be carefully examined.

One of the best candidates to use as monolayer builders are fatty acids. They are the mostly studied amphiphilic substances used as compound for gathering basic infor-

\footnotetext{
* corresponding author; e-mail: tomasz.martynski@put.poznan.pl
}

mation on the properties of the Langmuir monolayers [1-6]. Arachidic acid (AA) is an example of thoroughly characterized material in monolayers at the air-water interface. The state of the AA monolayer is strongly dependent on $\mathrm{pH}$ of the subphase. Attractive van der Waals interaction observed in acidic environment leads to densely packed structure. In contrast, dissociation of carboxylic groups results in electrostatic repulsion and larger area occupied by single AA molecule. Described difference in molecular organization of AA should have a significant influence on miscibility with additional compound in $2 \mathrm{D}$ system.

In this paper we present results of our study on Langmuir and LB films composed of perylene dye binary mixtures with arachidic acid in whole range of mole fraction and in wide range of subphase $\mathrm{pH}$. Perylene derivatives are very important fluorescent dyes for application in optoelectronics. Mixing of the dyes with monolayer builder molecules can improve orientation within monolayer and prevent the dye aggregation. Miscibility of the compounds in two-dimensional layer was investigated on the basis of recorded surface pressure-mean molecular area isotherms ( $\pi-A$ isotherms) and nanometric analysis of LB film textures by using atomic force microscope (AFM).

\section{Materials and methods}

Monoimide perylene dye derivatives of $3,4,9,10-$ perylenetetracarboxylic acid was synthesized and chromatographically purified at Institute of Polymer \& Dye Technology (Lodz University of Technology, Poland) [7]. Molecular structure of the dye and dimensions [8] of its rigid part are presented in Fig. 1. Arachidic acid with minimum purity of $99 \%$ was purchased from SigmaAldrich and used as received.

The Langmuir and LB monolayers were formed on a Minitrough 2 (KSV Instruments, Finland), equipped with PTFE $300 \times 75 \mathrm{~mm}^{2}$ trough and two symmetrically driven barriers, a strongly porous Wilhelmy plate 


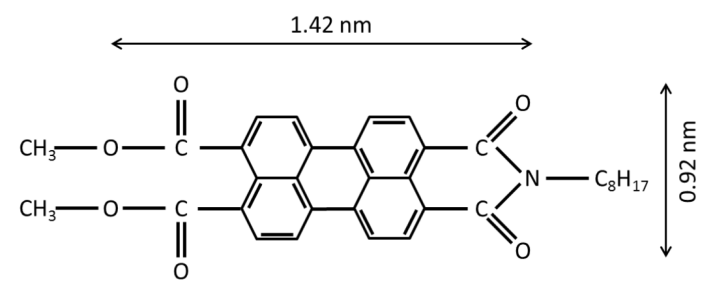

Fig. 1. Structure and dimensions of the investigated dye molecule.

hanging from an electronic balance for surface pressure measurements and a lift for the film transfer onto solid supports. The whole system is placed onto active antivibration table (Halcyonics, Germany). Ultrapure water used as a subphase was in first step purified by ion exchange resin and filtrated by Milli-Q system (Millipore Co., Austria) to receive purity with final specific resistance of $18.2 \mathrm{M} \Omega \mathrm{cm}$ at room temperature. Its $\mathrm{pH}$ was adjusted to the value of 3 and 13 by adding $0.1 \mathrm{M}$ $\mathrm{HCl}$ and $\mathrm{NaOH}$, respectively, and controlled by $\mathrm{pH}$ meter (CP-401 Elmetron, Poland). Subphase temperature was kept constant at $21^{\circ} \mathrm{C}$ by a cooling circulator (F12 Julabo, Germany).

Investigated substances were dissolved in chloroform (spectroscopic grade, $\mathrm{POCH}$, Poland) to get final concentration of $1 \mathrm{mM}$ of stock solutions. Mixtures of particular mole fraction were prepared from these stock solutions just before spreading. An appropriate amount (30-80 $\mu \mathrm{L})$ was deposited dropwise on a clean water surface from a microsyringe (Hamilton, Switzerland). The solvent was allowed to evaporate for $10 \mathrm{~min}$ after spreading. The film was then compressed symmetrically by two barriers at motion speed of $5 \mathrm{~mm} \mathrm{~min}^{-1}$ while $\pi-A$ isotherm was recorded under computer control. The measurements were reproducible within an error of $0.02 \mathrm{~nm}^{2}$ molecule ${ }^{-1}$.

Freshly cleaved mica sheets $\left(35 \times 20 \times 1 \mathrm{~mm}^{3}\right)$ were used as the solid substrates for the film deposition. Each sheet was rinsed with acetone to avoid any fragments left after the cleavage process. Monolayers were transferred at a rate of $5 \mathrm{~mm} \mathrm{~min}^{-1}$ by LB vertical dipping method. The films were stored in containers for less than $24 \mathrm{~h}$ before measurement.

Atomic force microscopy observations were performed in ambient conditions (in air, at $20-21^{\circ} \mathrm{C}$ ) on Innova Scanning Probe Microscope (Bruker, USA). The microscope was equipped with $100 \times 100 \mu \mathrm{m}^{2}$ piezoscanner and operating in intermittent contact mode. Height images were recorded using $\mathrm{Si}$ (P-doped) cantilevers with spring constant ranging from $20-80 \mathrm{~N} \mathrm{~m}^{-1}$ and resonant frequency of $247-303 \mathrm{kHz}$. The images were analyzed using WSxM software [9].

\section{Results and discussion}

\subsection{Surface pressure-mean molecular area isotherms}

A solution of AA in chloroform was spread onto freshly cleaned water subphase surface adjusted to proper $\mathrm{pH}$ in the Langmuir trough. Figure 2 presents the surface pressure-mean molecular area isotherms acquired during compression of arachidic acid on subphases adjusted to pH 3 and pH 13. Our isotherms are consistent with those presented in the literature [10]. It can be seen a significant dissimilarity between those two curves. The main difference is the value of $A_{\mathrm{EXT}}$ (Table) obtained by ex-

TABLE

Parameters of P1/AA mixtures in Langmuir films at mole fraction of $\mathrm{P} 1: M F=0,0.2,0.5,0.8,1$; compressed on subphase with $\mathrm{pH} 3$ and $\mathrm{pH} 13$. $A_{\mathrm{EXT}}-$ mean molecular area at the extrapolated tangent to the linear slope of the isotherms to the surface pressure $\pi=0$. $A_{\mathrm{K}}, \pi_{\mathrm{K}}-$ mean molecular area and surface pressure of liquid condensed to solid phase transition (for $\mathrm{pH} 3$ ) and plateau starting point (for $\mathrm{pH} 13$ ).

\begin{tabular}{l|c|c|c|c|c|c}
\hline \hline & \multicolumn{3}{|c|}{$\mathrm{pH} 3$} & \multicolumn{3}{|c}{$\mathrm{pH} 13$} \\
\cline { 2 - 6 } & $A_{\mathrm{EXT}}$ & $A_{\mathrm{K}}$ & $\pi_{\mathrm{K}}$ & $A_{\mathrm{EXT}}$ & $A_{\mathrm{K}}$ & $\pi_{\mathrm{K}}$ \\
\cline { 2 - 3 } \cline { 5 - 7 } & \multicolumn{2}{|c|}{$\left[\mathrm{nm}^{2}\right]$} & {$\left[10^{-3} \frac{\mathrm{N}}{\mathrm{m}}\right]$} & \multicolumn{2}{|c|}{$\left[\mathrm{nm}^{2}\right]$} & {$\left[10^{-3} \frac{\mathrm{N}}{\mathrm{m}}\right]$} \\
\hline $\mathrm{P} 1$ & 0.41 & - & - & 0.41 & - & - \\
$M F=0.8$ & 0.36 & 0.30 & 24.0 & 0.47 & - & - \\
$M F=0.5$ & 0.31 & 0.26 & 24.8 & 0.67 & 0.34 & 10.3 \\
$M F=0.2$ & 0.27 & 0.22 & 25.2 & 0.85 & 0.46 & 9.4 \\
$\mathrm{AA}$ & 0.23 & 0.19 & 25.5 & 0.90 & 0.50 & 8.0
\end{tabular}

trapolating the tangent to the linear slope of the isotherm to $\pi=0$. The $\pi-A$ isotherm formed at $\mathrm{pH} 3$ is typical for fatty acids and similar as for AA film compressed on pure water $(\mathrm{pH} \approx 7)[2,11]$. It can be divided into three areas each corresponding to a different phase of the monolayer and exhibits characteristic collapse behavior. In the case of the subphase with $\mathrm{pH} 13$ the situation is much more complex. The surface pressure starts to rise slowly for much larger area per molecule. The value of $A_{\mathrm{EXT}}$ is nearly four times larger than for the AA film compressed at subphase with $\mathrm{pH}$ 3. Further compression of the film results in "plateau" region on the isotherm. Fainerman et al. [10] interpreted this as a consequence of dissociation of $\mathrm{OH}$ group caused by high $\mathrm{pH}$ of the subphase. Their theoretical model predicts ionization of $15 \%$ of AA headgroups for monolayer compressed at subphase with $\mathrm{pH} 13$ and is negligible at $\mathrm{pH}$ below 12. These data are complemented with the Langmuir film textures, studied by using polarized light microscope BAM. They support the conclusion that condensed phase domains are formed after the break point in plateau region $A_{\mathrm{K}}$.

The isotherms of perylene dye $\mathrm{P} 1$ compressed on two subphases with strongly different $\mathrm{pH}$ are almost identical (compare isotherms of pure P1 films in Fig. 3a and b). That suggests orientation and density of the P1 molecules is not affected by concentration of $\mathrm{H}^{+}$ions in the subphase. The P1 molecules do not lay flat on the water but are tilted because the value of $A_{\mathrm{EXT}}$ is three times smaller than surface of the rigid part of $\mathrm{P} 1\left(A=1.3 \mathrm{~nm}^{2}\right)$.

Mixtures of P1/AA in chloroform were prepared by adding appropriate volumes of fresh stock solutions of both pure compounds and deposited by cospreading at 


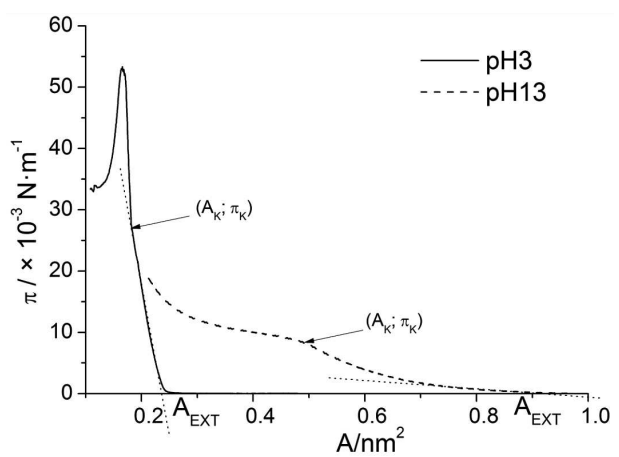

Fig. 2. Surface pressure-area isotherms of AA compressed on subphase with $\mathrm{pH} 3$ and $\mathrm{pH} 13$.
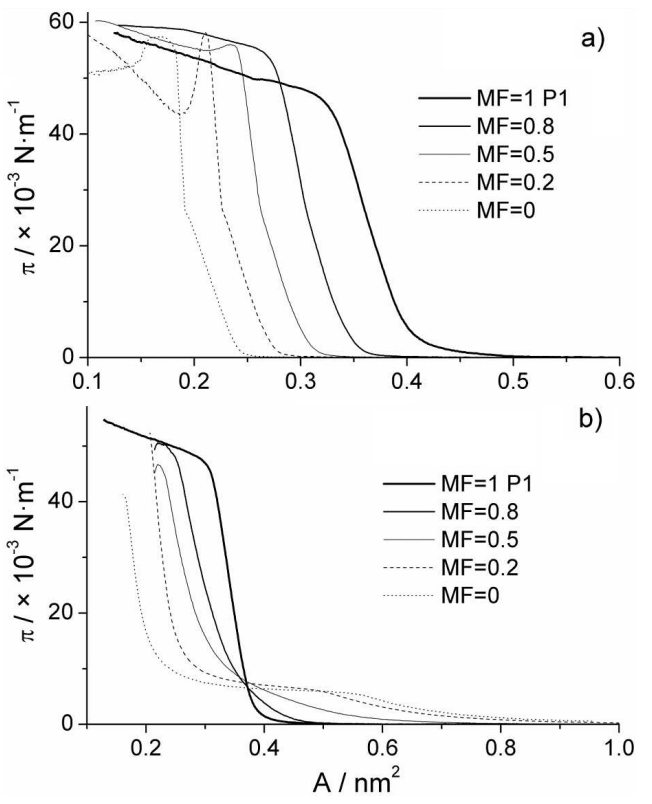

Fig. 3. Surface pressure-area isotherms of P1/AA mixtures in Langmuir films at mole fraction of P1: 0 , $0.2,0.5,0.8,1$; compressed on subphase with $\mathrm{pH} 3$ (a) and $\mathrm{pH} 13(\mathrm{~b})$.

clean air-subphase surface. Figure $3 \mathrm{a}$ and $\mathrm{b}$ shows isotherms for $\mathrm{P} 1$ dye mixed with $\mathrm{AA}$ at various mole fractions $(M F=0,0.2,0.5,0.8,1)$ compressed on acidic (Fig. 3a) and alkaline subphase (Fig. 3b). As it can be seen, $\mathrm{P} 1 / \mathrm{AA}$ mixtures under investigation can form stable and compressible monolayers at the air-subphase interface in whole range of the components concentration. Two sets of isotherms obtained for those acidic and alkaline subphases are very different. It is the consequence of the state of $\mathrm{AA}$ on subphases with such radically different concentration of $\mathrm{H}^{+}$ions. In Table main parameters of the films are given. For acidic subphase curves are located in sequence of the mole fraction of the dye. Extrapolated mean molecular area $A_{\mathrm{EXT}}$ increases with the value of $\mathrm{P} 1$ mole fraction. The isotherms for alkaline subphase can be divided into low and high surface pressure regions (approximately below and above $\left.10 \times 10^{-3} \mathrm{~N} \mathrm{~m}^{-1}\right)$. In first region isotherms are located in sequence of the mole fraction. At high surface pressures the order of the isotherms is reversed. It is connected with plateau part in the isotherm of pure AA film. The value of $A_{\mathrm{EXT}}$ decreases with the mole fraction of the dye $\mathrm{P} 1$, which is just in opposite to the case of subphase with $\mathrm{pH}$ adjusted to 3 .

To obtain information about miscibility from $\pi-A$ isotherms two parameters were analyzed: collapse surface pressure $\pi_{\mathrm{C}}$ and excess area [12], defined as:

$$
A_{\mathrm{E}}=A_{12}-\left(M F_{1} \times A_{1}+M F_{2} \times A_{2}\right),
$$

where $A_{12}$ is the mean molecular area for mixed monolayer with mole fractions $M F_{1}$ and $M F_{2}$ of the components, $A_{1}$ and $A_{2}$ are single component mean molecular areas determined at the same $\pi$. When ideal miscibility occurs, $A_{\mathrm{E}}$ is 0 as well as $\pi_{\mathrm{C}}$ alters with concentration of the components. On the other hand, when excess area criterion is maintained $\left(A_{\mathrm{E}}=0\right)$, but collapse surface pressure remains constant with changes of mole fraction, then complete phase separation takes place. Deviation from described situations results from non-ideal behavior and only partial miscibility. Plot of $A_{\mathrm{E}}$ versus mole fraction MF of the component reveals also interaction between components in the Langmuir film. Positive deviation of $A_{\mathrm{E}}$ from linear dependence $\left(A_{\mathrm{E}}>0\right)$ indicates a repulsive forces between components while negative deviation $\left(A_{\mathrm{E}}<0\right)$ is a sign of attractive forces.

Figure 4 shows calculated excess area per molecule for P1/AA mixtures in the Langmuir films at $\pi=10 \times$ $10^{-3} \mathrm{~N} \mathrm{~m}^{-1}$ for $\mathrm{pH} 3$ and $\pi=5 \times 10^{-3} \mathrm{~N} \mathrm{~m}^{-1}$ for $\mathrm{pH} 13$. It is seen that in the case when acidic subphase was used $A_{\mathrm{E}}$ is close to zero in the whole range of mole fraction of the dye. To determine whether ideal mixture or complete phase separation occurs collapse surface pressure must be analyzed. Due to thermodynamic stability of the monolayer, instead of collapse point we analyzed surface pressure of liquid condensed to solid phase transition in case of subphase with $\mathrm{pH} 3$ and plateau starting point for $\mathrm{pH} 13$. We denote these points with $\pi_{\mathrm{K}}$. The values of $\pi_{\mathrm{K}}$ were determined precisely from compression modulus (reciprocal of compressibility) $C_{\mathrm{S}}^{-1}$ vs. surface pressure curves (not presented), calculated according to equation:

$$
C_{\mathrm{S}}^{-1}=-A \times \frac{\mathrm{d} \pi}{\mathrm{d} A},
$$

which is a sensitive parameter on isotherm slope changes It can be easily seen that $\pi_{\mathrm{K}}$ (Table) remains almost constant in function of concentration which implies complete phase separation of the compounds.

For $\mathrm{pH} 13$ the value of excess area $A_{\mathrm{E}}$ changes with concentration of the dye. When there is large amount of $\mathrm{P} 1(M F \geq 0.5) A_{\mathrm{E}}$ is distinctly below 0 . This indicates non-ideal behavior and only partial miscibility. Area occupied by mixed monolayer is smaller than area occupied by the same amount of components in separate which indicates appearance of attractive interaction between molecules of the components in the monolayer But when the mole fraction is below 0.5 there is a mi- 


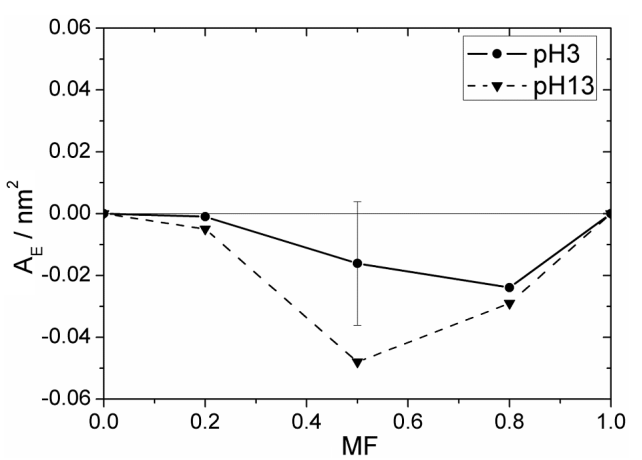

Fig. 4. Plot of excess area per molecule of the mixtures of P1/AA at $\pi=10 \times 10^{-3} \mathrm{~N} \mathrm{~m}^{-1}$ for subphase with pH 3 and at $\pi=5 \times 10^{-3} \mathrm{~N} \mathrm{~m}^{-1}$ for subphase with $\mathrm{pH}$ 13. The vertical bar represents measurement error $\Delta A_{\mathrm{E}}=0.02 \mathrm{~nm}^{2}$.

nor deviation from $A_{\mathrm{E}}=0$. While in the case of acidic subphase changes of $\pi_{\mathrm{K}}$ with mole fraction were negligible, for alkaline subphase the change is more significant.

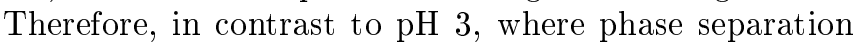
was postulated, we conclude that for $\mathrm{pH} 13$ ideal mixing of the components takes place.

At high surface pressures $\left(35 \times 10^{-3} \mathrm{~N} \mathrm{~m}^{-1}\right)$ there is a minor deviation from additivity rule $\left(A_{\mathrm{E}} \approx 0\right)$ in the whole range of mole fraction for both types of subphase. For acidic subphase the situation remains the same as observed at lower surface pressure, while for alkaline we conclude that higher concentration of the molecules change the interaction between compounds.

\subsection{Atomic force microscopy images}

Atomic force microscopy enables observation at the nanometric scale of the morphology of monolayers which were previously transferred onto atomically flat solid substrate. Freshly cleaved mica sheets were chosen for the LB films deposition. Imaging of LB films was carried out for pure AA and $\mathrm{P} 1$ and their mixtures with various mole fractions $(M F=0,0.3,0.7,1)$ of $\mathrm{P} 1$ formed on subphase adjusted to $\mathrm{pH} 3$ and $\mathrm{pH}$ 13. All monolayers created on acidic subphase were deposited at constant surface pressure $\pi=10 \times 10^{-3} \mathrm{~N} \mathrm{~m}^{-1}$. In case of $\mathrm{pH} 13$ deposition process took place at $\pi=5 \times 10^{-3} \mathrm{~N} \mathrm{~m}^{-1}$ on the first slope of the compression isotherms, before a plateau region. The pure P1 LB films were transferred onto mica at $\pi=10 \times 10^{-3} \mathrm{Nm}^{-1}$ for both types of subphases. The composition of mixed monolayers $(M F=0.3, M F=0.7)$ deposited for AFM experiments was chosen to easily distinguish between the areas covered by particular component.

AFM images of pure dye P1 monolayer created on both types of subphases at $\mathrm{pH} 3$ and $\mathrm{pH} 13$ are similar. Figure 5 presents the image of $\mathrm{P} 1$ film deposited from the subphase with $\mathrm{pH} 3$. Homogeneous monolayer with height of about $1.0 \mathrm{~nm}$ and numerous small bright spots with $2.0 \mathrm{~nm}$ height can be seen. We assign these to two forms of P1 - soft monomeric monolayer and rigid perylene aggregates. Strong tendency to aggregation of perylene derivatives were already described by many authors [1316]. The mica substrate is covered with P1 dye monolayer in almost $97 \%$ and in $3 \%$ with $\mathrm{P} 1$ aggregates for both types of LB films. Occasionally small black dots as a result of defects in the monolayer are seen in the picture and can be assigned to bare mica regions. These holes in the P1 film allowed us to measure the film thickness. The similarity in P1 LB film textures for both subphases is consistent with conclusion obtained from $\pi-A$ isotherms, that the film behave identically in those two distinct environments.

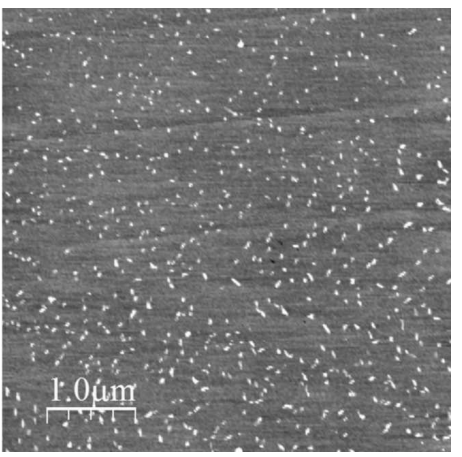

Fig. 5. Height image of P1 LB monolayer deposited at $\pi=10 \times 10^{-3} \mathrm{~N} \mathrm{~m}^{-1}$ from subphase with $\mathrm{pH} 3$. Scan size: $5 \times 5 \mu \mathrm{m}^{2}$.

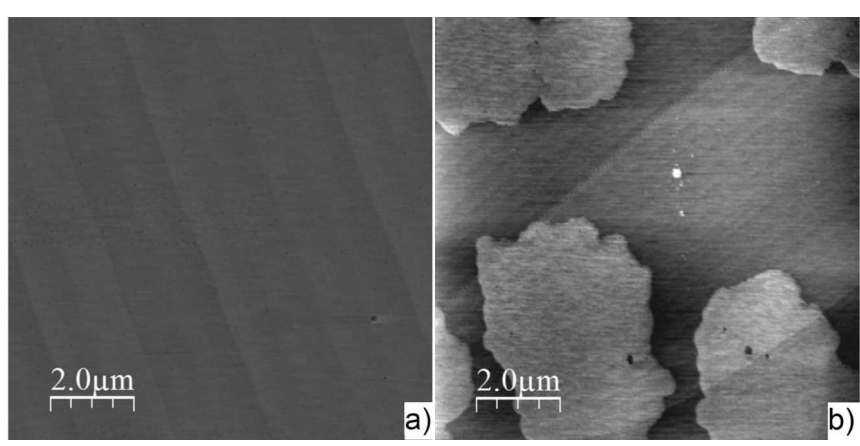

Fig. 6. Height image of AA LB monolayer deposited at $\pi=10 \times 10^{-3} \mathrm{~N} \mathrm{~m}^{-1}$ from subphase with $\mathrm{pH} 3$ (a) and at $\pi=5 \times 10^{-3} \mathrm{~N} \mathrm{~m}^{-1}$ from subphase with pH 13 (b). Scan size: $10 \times 10 \mu \mathrm{m}^{2}$.

Images of pure arachidic acid monolayer created on pH 3 (Fig. 6a) and pH 13 (Fig. 6b) subphase are very different. In the first image (Fig. 6a) a flat, homogeneous monolayer covering the mica substrate in $100 \%$ is visible. The second image (Fig. 6b) shows the monolayer consisting of condensed phase domains which cover about $40 \%$ of the substrate surface. Difference in coverage derives from various mean molecular areas at which monolayers were transferred onto mica $\left(A=0.22 \mathrm{~nm}^{2}\right.$ and $A=0.56 \mathrm{~nm}^{2}$, respectively). Wide gray strips across the scan images are scanning artifacts. Vollhardt et al. [10] 
present in their paper polarized optical microscope images (BAM) of the Langmuir films formed by AA at subphase with $\mathrm{pH} 13$ recorded in the plateau region of the surface pressure isotherm. In their paper (see Fig. 3d in [10]) irregular structures are present, which are much larger in lateral dimensions than the scanning area of our AFM images $\left(10 \times 10 \mu \mathrm{m}^{2}\right)$. Because of used experimental method, their observations were performed after plateau starting point $\pi_{\mathrm{K}}\left(\pi>\pi_{\mathrm{K}}\right)$ of the Langmuir film at much larger scale of field of view (the best lateral resolution of the BAM is higher than $2 \mu \mathrm{m})$. As one can see from our AFM image (Fig. 6b), these phenomena can be observed as early as the monolayer begins to form (for mean molecular areas lower than $A_{\mathrm{C}}$ ). Height measured for both films versus bare mica substrates is the same and equals $0.7 \mathrm{~nm}$. AA monolayer deposited onto mica at $\pi=10 \times 10^{-3} \mathrm{~N} \mathrm{~m}^{-1}$ for $\mathrm{pH} 3$ and $\pi=5 \times 10^{-3} \mathrm{~N} \mathrm{~m}^{-1}$ for $\mathrm{pH} 13$ are in liquid condensed and liquid expanded state, respectively. In such films alkyl chains are not ordered vertically to the substrate. Taking into account length of AA molecule, we assume bending of supple hydrocarbon chains due to stress produced by cantilever onto soft molecular brush during scanning the AA film, therefore measured heights of the films are not realistic.

Figure $7 \mathrm{a}$ and $\mathrm{b}$ presents topography of P1/AA mixture monolayer with two concentrations of $\mathrm{P} 1$ dye equal to $M F=0.3$ and $M F=0.7$ formed at $\mathrm{pH} 3$ subphase. The mica surface is almost completely covered by the film. On both images tri-level monolayer is visible with heights: $1 \mathrm{~nm}(\mathrm{~A}), 2 \mathrm{~nm}$ (B) and $1.5 \mathrm{~nm}(\mathrm{C})$. The brightest small domains (B) appear against homogeneous film (A) have the same height and texture as the pure P1 LB film presented in Fig. 5. Therefore, we identify these areas as the two forms of perylene dye film (tilted and vertically aligned), the same as they appear in pure P1 monolayer (Fig. 5). Taking into account the fact that the substrate area coverage by areas $\mathrm{A}$ and $\mathrm{B}$ are proportional to the dye content in the mixture $(21 \%$ for $M F=0.3$ and $77 \%$ for $M F=0.7)$, it allows us to assign area $\mathrm{C}$ to arachidic acid. A vestigial form of the components miscibility, which is in good agreement with conclusions from $\pi-A$ measurements, can explain the discrepancy between the dye concentration (MF) and the substrate coverage. Presence of additional compound molecules (in this case P1) even at very low concentration (e.g. 1:100) [17] in the monolayer can result in different molecular organization and thus the height. Large difference molecular structure of P1 and AA can significantly change alignment of the film, which is predominantly formed by the latter.

In a similar way two mixed LB films with $M F=0.3$ and $M F=0.7$ of the dye deposited from subphase with pH 13 were characterized. From the Langmuir film measurements on mixed monolayer with $M F=0.3$ of $\mathrm{P} 1$ almost complete miscibility is postulated, as described above. This film was transferred at $\pi=5 \times 10^{-3} \mathrm{~N} \mathrm{~m}^{-1}$ onto mica substrate. In Fig. $8 \mathrm{a}$ the AFM $10 \times 10 \mu \mathrm{m}^{2}$ topography image of the LB monolayer is presented. A
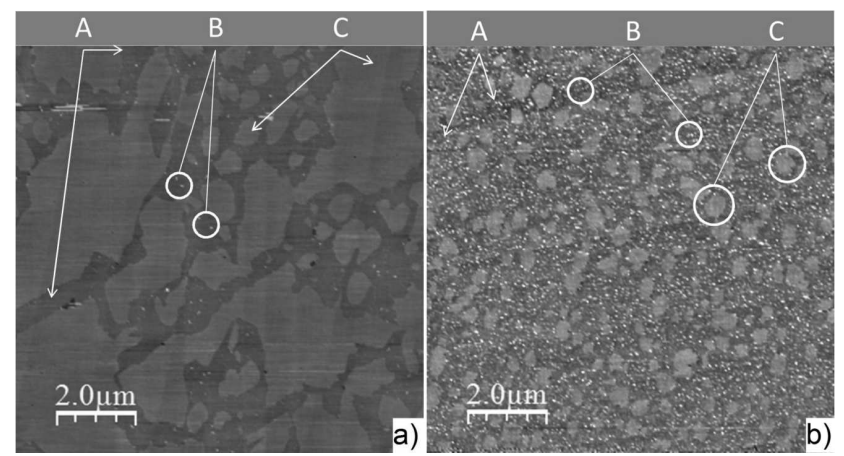

Fig. 7. Height image of P1/AA mixture LB monolayer with $\mathrm{P} 1 M F=0.3$ (a) and $M F=0.7$ (b), deposited at $\pi=10 \times 10^{-3} \mathrm{~N} \mathrm{~m}^{-1}$ from subphase with $\mathrm{pH} 3$. Scan size: $10 \times 10 \mu \mathrm{m}^{2}$.

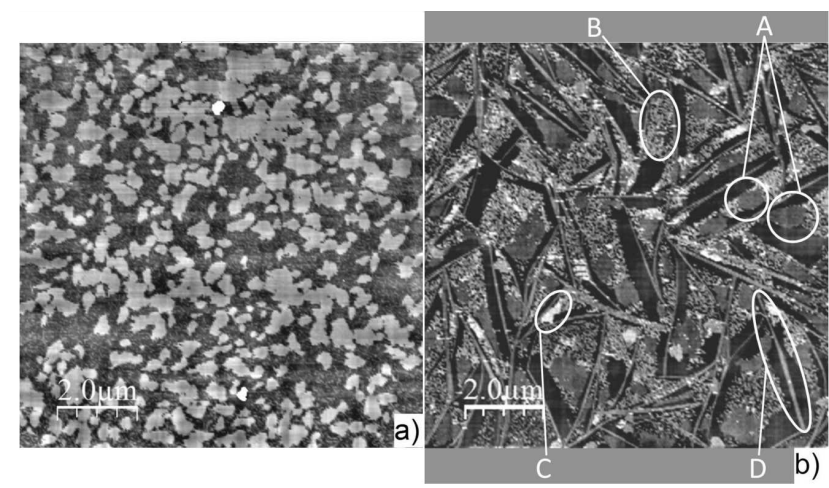

Fig. 8. Height image of P1/AA mixture LB monolayer with $\mathrm{P} 1 M F=0.3$ (a) and $M F=0.7$ (b), deposited at $\pi=5 \times 10^{-3} \mathrm{~N} \mathrm{~m}^{-1}$ from subphase with $\mathrm{pH} 13$. Scan size: $10 \times 10 \mu \mathrm{m}^{2}$.

number of irregular domains of $1.5 \mathrm{~nm}$ height and submicrometer in lateral dimensions are observed. No signs of crystalline forms, observed for the pure dye monolayer, were found. Presence of only one type of the structure in the AFM image is a sign of the components miscibility. Interaction between molecules of the components lead to size reduction of observed domains in lateral dimensions in mixed monolayer comparing to those observed for pure arachidic acid film (Fig. 6b). We found only a few forms with $0.7 \mathrm{~nm}$ in height, which we assign to $\mathrm{P} 1$ molecules. This behavior is the consequence of almost complete miscibility of the compounds in the monolayer in low range of P1 concentration, where only small precipitations of P1 are present.

Behavior of the components in mixed monolayer deposited from the water with $\mathrm{pH} 13$ and $M F=0.7$ of $\mathrm{P} 1$ is more complex. Topography of the film is shown in Fig. 8b. The monolayer covers about $65 \%$ of the substrate surface. Circular domains with $0.7 \mathrm{~nm}$ height (A) and irregular area with $1.5 \mathrm{~nm}$ (C) are surrounded by rough, $1 \mathrm{~nm}$ high film (B) and bare mica regions (the most dark surface). Textures with rough surface were 
frequently observed by us for other monoimide perylene dyes in AFM investigations. Moreover, similarity of height values of areas $\mathrm{A}$ and $\mathrm{B}$ to pure compound monolayers and, e.g. [7], indicates that these are regions covered with separate components (AA and $\mathrm{P} 1$, respectively). From previous analysis $(M F=0.3, \mathrm{pH} 13$; Fig. $8 \mathrm{a})$ we conclude that the components are miscible when the mole fraction of the dye is below $M F<0.3$ in agreement with calculated coverage. Miscibility areas (C) occurring alongside pure compound regions, cover about $10 \%$ of the whole substrate area, which constitutes $15 \%$ of the surface covered by the monolayer. Partial miscibility is also in agreement with excess area $A_{\mathrm{E}}$ calculation. The image reveals also existence of narrow strips (D) with height of $1 \mathrm{~nm}$ and micrometers length. The strips can be ascribed to crystalline forms of P1. Similar elongated aggregates were observed by Wang et al. [18]. The aggregates are formed in consequence of $\pi-\pi$ stacking of perylene dyes $\pi-A$ isotherm analysis indicated that area occupied by mixed monolayer is smaller than area occupied by the same amount of the separated components. This resulted in negative value of excess area $A_{\mathrm{E}}$, which can be explained by formation of elongated crystallites of perylene dye molecules.

\section{Conclusions}

In this study the Langmuir technique and the atomic force microscopy have been applied for investigation of miscibility in two component mixtures of arachidic acid with perylene derivative dye as a function of subphase $\mathrm{pH}$. The analysis of the surface pressure-mean molecular area isotherms of the Langmuir films of pure components and their mixtures in whole range of mole fraction reveals that the miscibility of components strongly depends on the type of subphase $\mathrm{pH}$ on which the films are compressed and the dye concentration.

The mixtures isotherm analysis and the excess area $A_{\mathrm{E}}$ at the surface pressure below the first kink in the isotherm courses, at $\pi=10 \times 10^{-3} \mathrm{~N} \mathrm{~m}^{-1}$ for subphase with $\mathrm{pH} 3$ reveals phase separation of the components in a whole range of $\mathrm{P} 1$ concentration. For the Langmuir films formed at the subphase with $\mathrm{pH} 13$ at $\pi=5 \times 10^{-3} \mathrm{~N} \mathrm{~m}^{-1}$ the study reveals miscibility of $\mathrm{P} 1$ below $M F=0.3$ and phase separation at higher concentrations. Careful analysis of the AFM morphology images allowed to verify phase separation in case of the LB films deposited from pH 3 and complete miscibility for the films with low concentration of P1 formed at the subphase with $\mathrm{pH} 13$. The AFM images clearly demonstrate the differences between mixed and separated phases when partial miscibility was postulated in the case of high concentration of $\mathrm{P} 1$ where four phases are seen: separated AA and P1, mixed P1/AA and crystallites of P1.

For better insight into the complex miscibility process in $2 \mathrm{D}$ system it is necessary to use not only a thermodynamic analysis but complementary techniques such as AFM imaging the film morphology, especially when partial miscibility takes place.

\section{Acknowledgments}

This work was financially supported by Polish Ministry of Science and Higher Education under grant No. DS 64/413/2013. JM is a scholar within Sub-measure 8.2.2 Regional Innovation Strategies, Measure 8.2 Transfer of knowledge, Priority VIII Regional human resources for the economy Human Capital Operational Program cofinanced by European Social Fund and state budget.

\section{References}

[1] W.D. Harkins, The Physical Chemistry of Surface Films, Reinhold Publishing Corp., New York 1952.

[2] G.L. Gaines, Insoluble Monolayers at Liquid-gas Interfaces, Interscience Publishers, New York 1966.

[3] N.R. Pallas, B.A. Pethica, Langmuir 1, 509 (1985).

[4] A.M. Bibo, C.M. Knobler, I.R. Peterson, J. Phys. Chem. 95, 5591 (1991).

[5] P.B. Miranda, Q. Du, Y.R. Shen, Chem. Phys. Lett. 286, 1 (1998).

[6] J.B. Peng, G.T. Barnes, I.R. Gentle, Adv. Colloid Interface Sci. 91, 163 (2001).

[7] R. Hertmanowski, E. Chrzumnicka, J. Makowiecki, T. Martynski, J. Paluszkiewicz, R. Stolarski, D. Bauman, Soft Mater. 12, 1 (2014).

[8] P.A. Antunes, C.J.L. Constantino, R.F. Aroca, J. Duff, Langmuir 17, 2958 (2001).

[9] I. Horcas, R. Fernandez, J.M. Gomez-Rodriguez, J. Colchero, J. Gomez-Herrero, A.M. Baro, Rev. Sci. Instrum. 78, 013705 (2007).

[10] V. B. Fainerman, D. Vollhardt, R. Johann, Langmuir 16, 7731 (2000).

[11] Hoenig, D. Moebius, J. Phys. Chem. 95, 4590 (1991).

[12] M.C. Petty, Langmuir-Blodgett Films: An Introduction, Cambridge University Press, Cambridge UK 1996.

[13] T. del Cano, V. Parra, M.L. Rodriguez-Mendez, R. Aroca, J.A. de Saja, Org. Electron. 5, 107 (2004).

[14] D. Bauman, R. Hertmanowski, K. Stefańska, R. Stolarski, Dyes Pigments 91, 474 (2011).

[15] T. Martynski, R. Hertmanowski, R. Stolarski, D. Bauman, Thin Solid Films 516, 8834 (2008).

[16] A. Tolkki, E. Vuorimaa, V. Chukharev, H. Lemmetyinen, P. Thalainen, J. Peltonen, V. Dehm, F. Würthner, Langmuir 26, 6630 (2009).

[17] M. Van der Auweraer, B. Verschuere, F.C. De Schryver, Langmuir 4, 583 (1988).

[18] G. Fu, N. Xia, Y. Wang, M. Yang, G. Zhang, W. Wang, Mater. Lett. 63, 409 (2009). 